\title{
Air temperature-related human health outcomes: Current impact and estimations of future risks in Central Italy
}

\author{
Marco Morabito ${ }^{\mathrm{a}, \mathrm{e}, *}$, Alfonso Crisci ${ }^{\mathrm{c}}$, Marco Moriondo ${ }^{\mathrm{c}}$, Francesco Profili ${ }^{\mathrm{b}}$, Paolo Francesconi ${ }^{\mathrm{b}}$, \\ Giacomo Trombi f,g, Marco Bindi ${ }^{\mathrm{f}}$, Gian Franco Gensini ${ }^{\mathrm{a}, \mathrm{d}}$, Simone Orlandini ${ }^{\mathrm{a}, \mathrm{e}}$ \\ a Interdepartmental Centre of Bioclimatology, University of Florence, Piazzale delle Cascine 18, 50144 Florence, Italy \\ ${ }^{\mathrm{b}}$ Osservatorio di Epidemiologia, Agenzia Regionale di Sanità della Toscana, Via Pietro Dazzi, 1 Villa La Quiete alle Montalve, 50141 Florence, Italy \\ ${ }^{\mathrm{c}}$ Institute of Biometeorology, National Research Council, Via Giovanni Caproni 8, 50145 Florence, Italy \\ d Clinica Medica e Cardiologia, University of Florence, Viale Morgagni 85, 50134 Florence, Italy \\ e Centre for Civil Protection and Risk Studies, University of Florence (CESPRO), Viale Morgagni 48, 50134 Florence, Italy \\ ${ }^{\mathrm{f}}$ Department of Plant, Soil and Environmental Science, University of Florence, Piazzale delle Cascine 18, 50144 Florence, Italy \\ ${ }^{g}$ International Institute for Applied Systems Analysis (IIASA), Risk and Vulnerability (RAV) Program, Disasters, Adaptation and Development (DAD) Group, Schlossplatz 1, \\ A-2361 Laxenburg, Austria
}

\section{H I G H L I G H T S}

- We have evidenced contrasting temperature-impact patterns between mortality and hospitalizations.

- We have examined geographical differences in temperature-related human health outcomes.

- Predictions of future city-specific impact of climate change on human health have been provided.

- A slight unexpected increase of short-term cold-related mortality in the very elderly is predicted in several cities.

- General increases of annual temperature-related mortality rates are expected, highest values will be in coastal plain cities.

\section{A R T I C L E I N F O}

\section{Article history:}

Received 12 July 2012

Received in revised form 19 September 2012

Accepted 23 September 2012

Available online 4 November 2012

\section{Keywords:}

Mortality

Hospitalization

Distributed lag model

Cold

Heat

Climate-change scenario

\begin{abstract}
A B S T R A C T
The association between air temperature and human health is described in detail in a large amount of literature. However, scientific publications estimating how climate change will affect the population's health are much less extensive. In this study current evaluations and future predictions of the impact of temperature on human health in different geographical areas have been carried out. Non-accidental mortality and hospitalizations, and daily average air temperatures have been obtained for the 1999-2008 period for the ten main cities in Tuscany (Central Italy). High-resolution city-specific climatologic A1B scenarios centered on 2020 and 2040 have been assessed. Generalized additive and distributed lag models have been used to identify the relationships between temperature and health outcomes stratified by age: general adults $(<65)$, elderly (aged 65-74) and very elderly ( $\geq 75$ ). The cumulative impact (over a lag-period of 30 days) of the effects of cold and especially heat, was mainly significant for mortality in the very elderly, with a higher impact on coastal plain than inland cities: $1{ }^{\circ} \mathrm{C}$ decrease/increase in temperature below/above the threshold was associated with a $2.27 \%$ (95\% CI: $0.17-4.93)$ and $15.97 \%$ (95\% CI: 7.43-24.51) change in mortality respectively in the coastal plain cities. A slight unexpected increase in short-term cold-related mortality in the very elderly, with respect to the baseline period, is predicted for the following years in half of the cities considered. Most cities also showed an extensive predicted increase in short-term heat-related mortality and a general increase in the annual temperature-related elderly mortality rate. These findings should encourage efforts to implement adaptation actions conducive to policy-making decisions, especially for planning short- and long-term health intervention strategies and mitigation aimed at preventing and minimizing the consequences of climate change on human health.
\end{abstract}

(c) 2012 Elsevier B.V. All rights reserved.
Abbreviations: GAMs, Generalized Additive Models; IPCC, Intergovernmental Panel on Climate Change; HadRM3P, Hadley Centre Regional Model version 3P; ICD, International Classification of Diseases.

* Corresponding author at: Interdepartmental Centre of Bioclimatology, University of Florence, Piazzale delle Cascine 18, 50144 Florence, Italy. Tel.: + 3955 5226041; fax: + 3955444083 .

E-mail address: marco.morabito@unifi.it (M. Morabito).

\section{Introduction}

The association between air temperature and human health has been demonstrated in many parts of the world and is described in detail in numerous recent reviews (Conlon et al., 2011; Kovats and Hajat, 2008; Ye et al., 2012; Yu et al., 2011). Commonly, immediate or very 
short time scale impact, especially on mortality events, has been observed for high temperatures (Morabito et al., 2012; Muggeo and Hajat, 2009). Conversely, cold weather generally showed a delayed health effect up to several weeks (Analitis et al., 2008; Armstrong, 2006; Muggeo and Hajat, 2009). However, exceptions have recently been described and hospitalizations for specific types of diseases showed an evident immediate cold effect (Morabito et al., 2011).

Several studies showed a greater impact of temperature on mortality than on hospitalizations, especially when extremely high values were reached, with clearly contrasting patterns (Kovats et al., 2004; Linares and Díaz, 2008; Mastrangelo et al., 2006). Generally, U-, V-, or J-shaped relationships have been described (Armstrong, 2006; Iñiguez et al., 2010; McMichael et al., 2008; Ye et al., 2012) and specific temperature thresholds (or optimum temperatures), initially calculated to recognize the minimum mortality level (Kalkstein and Davis, 1989), have been assessed in many cities worldwide. Only a few studies have tried to identify clear temperature thresholds for morbidity events (Kovats et al., 2004; Lin et al., 2009). Starting from these cityspecific optimum temperatures, the mortality/morbidity begins to rise with a slope depending on geographical location. The temperaturemortality/morbidity relationship varies greatly depending on latitude, climatic zone and demographic characteristics, showing the worst impact on the elderly population because mostly susceptible to temperature changes (Hajat et al., 2007). Several studies also demonstrated that people living in warmer cities are more affected by lower temperatures and, conversely, people in colder cities suffer from warmer temperatures (Iñiguez et al., 2010; Keatinge et al., 2000a; The Eurowinter Group, 1997). All this information assumes great significance in terms of public health, especially in the light of future climate-change projections provided by climatic scenarios, currently adopted by the community research of climatologists. Since the Intergovernmental Panel on Climate Change (IPCC) indicated that the world average temperature would continue to increase (IPCC, 2007), and because a continuous growth of the elderly population and consequently of the fraction of frail elderly, is expected mainly in industrialized countries (United Nations, Department of Economic and Social Affairs, Population Division, 2011), great attention should be paid to the risk estimation of the potential impact of climate change on human health.

Nowadays, scientific publications estimating how climate change will affect the population's health are much less extensive (McMichael et al., 2006). Since most temperate industrialized countries show a typical seasonal mortality with a winter peak, it has been hypothesized that future winters predicted to be milder should reduce the mortality risk due to cold weather (Langford and Bentham, 1995). On the other hand, as reported in a detailed critical review (Gosling et al., 2009), an increase in heat stress and heat-related mortality, especially among the elderly, is also predicted under different climatologic scenarios. However, at the moment, there is still discrepancy and uncertainty in evaluating the magnitude of these changes and an accurate estimation of the burden of the annual temperature-related mortality will help better understand the potential impact of climate change on human health.

For these reasons, three main issues have been investigated in this study: 1) current quantitative evaluations of the impact of air temperature on two significant health outcomes that were carried out over a 10-year period (1999-2008): non-accidental mortality and hospitalizations; 2) investigations of regional geographical differences of the relationship between temperature and human health; 3 ) predictions of future city-specific impact of climate change on human health.

For this purpose, generalized additive models (GAMs) and distributed lag models were used to account for the non-linear effect of temperature and to quantify the immediate/delayed health effects of exposure to both cold and heat. Subsequently, high-resolution city-specific climatologic scenarios for two 20-year periods centered on 2020 and 2040, produced by the Hadley Centre Regional Model version 3P (HadRM3P) simulations, were used to predict city-specific short-term changes in temperature-related annual mortality rates for the following near (2011-2030) and distant (2031-2050) 20-year periods.

\section{Material and methods}

\subsection{Health outcome data and study area}

The study was carried out over an area of approximately $23 \mathrm{~km}^{2}$ located in Central Italy (Tuscany) which had approximately 3.7 million inhabitants in 2008. Health outcome data comprised residents of the 10 major cities in Tuscany who died or were hospitalized for nonaccidental causes in the cities between 1999 and 2008. Non-accidental mortality and hospital admission data (ICD9<800) were provided by the Mortality Registry and the Hospitalization Registry of the Tuscany Region.

The geographical locations of the 10 cities were used to classify them in three city-specific homogeneous areas in climatic and altitudinal terms (See Supplementary material, online Fig. 1): a) Inland plain, which includes the cities of Florence, Prato, Pistoia and Lucca, at an average altitude and distance from the Tyrrhenian Sea of about $50 \mathrm{~m}$ a.s.l. and $55 \mathrm{~km}$ respectively. The average urban population density for the 10-year period studied was about 1550 inhabitants per $\mathrm{km}^{2}$. The percentages of elderly (aged 65-74) and very elderly $(\geq 75)$ population were $11.6 \%$ and $11.5 \%$ respectively, while the old age index, that is a measure of the relationship between the population over the age of 65 divided by the population under the age of 15 (values higher than 100 indicate more elderly people than the young ones), was 177.0. b) Coastal plain, which comprises the cities of Massa-Carrara, Livorno, Pisa and Grosseto, at an average altitude and distance from the Tyrrhenian Sea of about $20 \mathrm{~m}$ a.s.l. and $7 \mathrm{~km}$ respectively. The average urban population density was about 910 inhabitants per $\mathrm{km}^{2}$. The percentages of elderly and very elderly population were $11.4 \%$ and $10.7 \%$ respectively, while the old age index was 205.0. c) Inland hill, which includes the cities of Siena and Arezzo, at an average altitude and distance from the Tyrrhenian Sea of $310 \mathrm{~m}$ a.s.l. and $89 \mathrm{~km}$ respectively. The average urban population density was about 349 inhabitants per $\mathrm{km}^{2}$. The percentages of elderly and very elderly population were $12.2 \%$ and $12.7 \%$ respectively, while the old age index was 199.2.

Additionally, for the period under study, the average percentage of people older than 64 years accounted for as much as $58 \%$ of all people living alone in Tuscany. Furthermore, only $15.2 \%$ of families held a domestic air conditioner; on the other hand, $96.2 \%$ of families held a heating system (source: the Italian National Institute of Statistics http://sitis.istat.it/sitis/html/).

With regard to the climate features of the areas studied, July and August represent the warmest months in all the geographical areas investigated, while the coldest months are December and January. The inland plains/hills are characterized by the highest/lowest temperatures respectively. Inland cities experienced the highest number of freezing days during winter, especially in rural areas. Furthermore, the daily temperature range is high, especially in the inland hill cities and during the warmest months. Conversely, coastal plain cities are generally characterized by a milder climate due to the influence of the sea, and also show the lowest daily temperature range with rare extreme temperatures.

\subsection{Meteorological data}

For each of the 10 cities in Tuscany, the daily average air temperature dataset was provided for the 1999-2008 period by means of the Daymet procedure (Thornton et al., 1997). Daymet is a software package that produces daily meteorological data over large regions, taking into account the effects of terrain morphology. Meteorological observations can be included from an arbitrarily large number of stations that are used to fit a locally calibrated relationship of temperature 
and precipitation to elevation. This software, in addition to daily meteorological observations from a network of weather stations, requires a Digital Terrain Model of the study region, which in our case has a spatial resolution of $200 \times 200 \mathrm{~m}$. For further information on Daymet and for a detailed description of its calibration for the Tuscany region, refer to Chiesi et al. (2007). The selection of the grid points belonging to the 10 cities considered in this study was made by using the Corine Land Cover database (European Topic Centre on Terrestrial Environment, 2000). This useful product represents a comprehensive combination of landscape information deriving from remote sensing and other data sources. Following, the selected grid points, corresponding to the geographical position of each city, were aggregated by calculating the mean daily air temperature values.

\subsection{Climatologic scenarios}

Output data of climate simulations from the dynamic Regional Climate Model, the Hadley Centre Regional Model version 3P (HadRM3P), were used as drivers to evaluate the potential effects of climate change on human health. The HadRM3P is the model incorporated in the regional climate modeling system "Providing Regional Climates for Impacts Studies", developed and freely distributed by the Hadley Centre. The HadRM3P has a grid-spacing of $0.44^{\circ}$ latitude by $0.44^{\circ}$ longitude, corresponding to a horizontal resolution of about $50 \mathrm{~km}$. Because the climatic-impact community requires an increase in spatial resolutions to assess vulnerability and potential adaptation strategies in the climate-change scenario, the outputs from the HadRM3P were statistically downscaled over the 10 urban areas using an additional reference tool: the LARS-WG stochastic weather generator as described in Semenov and Barrow (1997). The LARS-WG downscaling procedure includes a proper training stage where the observed daily weather data were used to identify the best set of parameters related to the probability distributions of weather variables in each location. These parameters were then used to generate synthetic daily site-specific weather time series, with an arbitrary length, taking into account the forcing factors derived from the Local Climate Scenario. Time series with a 30-year arbitrary length were used and the forcing factors, as established by LARS-WG, were calculated in terms of monthly future climatic deviation minimum and maximum temperatures, rainfall and radiation with respect to the baseline of each parameter. The temporal variability of temperature and rainfall, as relative change in standard deviation and in duration of wet and dry spells, was also calculated and included. Finally, for each of the 10 cities considered, two 20-year periods of A1B climatologic temperature scenario (IPCC, 2000), centered on the years 2020 (2011-2030) and 2040 (2031-2050), were assessed. Based on the IPCC special report (IPCC, 2000), the A1B emission scenario assumes a future world with very rapid economic growth, low population growth (the global population peaks in mid-century and declines thereafter) and rapid introduction of new and more efficient technology.

\subsection{Statistical analyses}

All statistical analyses were conducted with the R statistical software version 2.13.2 (R Development Core Team, 2011).

A preliminary descriptive analysis was performed to investigate the seasonal fluctuation of both mortality and hospitalizations, and the daily average air temperature. Significant fluctuations were detected by using a non-parametric procedure (the Kruskal-Wallis Test) for mortality and hospitalization data, while a parametric procedure (ANOVA) was used for the air temperature. The descriptive analysis and the following retrospective investigation to estimate the current impact of temperature on health outcome data, were carried out by grouping the cities in 3 specific geographical areas (inland plain, coastal plain and inland hill) previously described in Section 2.1 . The analyses were also stratified by age: general adults $(<65)$, elderly (aged 65-74) and very elderly ( $\geq 75)$. Because it is well known that the effects of excessive heat and especially cold conditions on mortality are not limited to the same day-exposure, but could extend to several following days (also several weeks) (Analitis et al., 2008; Armstrong, 2006; Muggeo and Hajat, 2009), an innovative statistical approach called "constrained segmented distributed lag model", fully described in Muggeo (2010), was adopted (See Supplemental material, online Fig. 2). In particular, a specific R statistical package, "modTempEff" (version 1.5) (Muggeo, 2008, 2010), available from the Comprehensive R Archive Network (http://CRAN.R-project.org/ package $=$ modTempEff), was used. This package fits a Poisson log-linear regression model to assess the effects of temperature on mortality or morbidity using a specific approach (the constrained segmented distributed lag parameterization) which allows for simultaneously calculating the two main effects of temperature exposure on health data: 1) the non-linearity, and 2) the distributed lag effect. A maximum 30-day time-lag was considered as a sufficient length of time to estimate any possible delayed short-term excess/deficit due to exposure to both cold and heat. This statistical package was applied to the time series for each geographical area considered and the analyses were always controlled for specific Boolean confounders included in the model: the year, the season (winter: December-February; spring: March-May; summer: June-August; and autumn: SeptemberNovember) and the day of the week, national celebrations and finally, the summer population decrement. Single temperature thresholds were estimated (See Supplementary material, online Fig. 2) for each geographical area through an algorithm, directly integrated in this statistical package, able to detect breakpoints. These thresholds correspond to the temperature where the linear relationship between the dependent and independent variables shows a change along the range, and where normally the mortality or morbidity starts to increase significantly with respect to the temperature variation.

The summarized results show all the parameters estimated: the temperature thresholds and the correspondent percentile values, the number of days above/below temperature thresholds, and the cumulative effect (that is, the net heat and cold effect assessed as the summation of risks at all individual lags) with confidential intervals, the peak lag and the effect at peak lag represented by the \% change in mortality or morbidity events per $1{ }^{\circ} \mathrm{C}$ decrease/increase of air temperature respectively below/above the previous identified threshold. In addition, graphics representing distributed lag curves for cold and heat effects are also shown for each geographical area.

Finally, future city-specific health risk estimations were projected by driving the statistical heath risk models for two downscaled and calibrated 20-year periods of A1B temperature scenarios (See Supplementary Material, online Fig. 2). For these purposes, generalized additive models (GAMs) (Hastie and Tibshirani, 1995) were used. GAMs are very flexible tools that allow for applying a wide variety of link functions on the dependent variable for taking any non-linear (smooth) effect of predictor variables into account. A Poisson link assumption was used in this study. The use of these models has a double goal: 1) to maintain a robust inferential scheme, and 2) to maximize the quality of prediction of any dependent variable considered. The GAM procedure was applied by the R "mgcv" package (Wood, 2006) and was systematically used throughout the entire investigation period to estimate the smoothed shape of exposure-response curves between mortality/ hospitalizations and short-term changes in temperature. The latter was calculated by averaging the daily mean temperature value on a specific day with that calculated on the previous day $\left(\operatorname{lag}_{0-1}\right)$. Breakpoints (critical temperature thresholds) were also identified by using the $\mathrm{R}$ "segmented" statistical package (Muggeo, 2003), which is equivalent to the algorithm integrated in the R "modTempEff" statistical package previously described. The $\mathrm{R}$ "mgcv" package was used to compute the full parameterization of retrospective GAM models, also controlled for calendar factor confounders such as seasons, days of the week, celebrations, and summer population decrement. Afterwards, these models were used in a predictive manner, adopting downscaled and calibrated 
climatic scenario data to obtain city-specific projections of future shortterm changes in temperature-related health risks (see Supplementary material, online Fig. 2).

The summarized results show the predicted \% change in health outcome data per $1{ }^{\circ} \mathrm{C}$ future increase/decrease above/below the critical temperature threshold for the following near (centered on the 2020: 2011-2030) and distant (centered on the 2040: 2031-2050) 20 -year periods. Furthermore, mortality changes $(\Delta)$ predicted for the 2020 and 2040 periods, with respect to the reference base period (1999-2008), are indicated by directional arrow icons ( $\downarrow$ decreased; $\uparrow$ increased; $\leftrightarrow$ unchanged) and absolute $\Delta$ values, that correspond to the predicted deviation from the reference base period.

Graphical representations of city-specific health risk estimations, grouped by geographical area, are also shown. Graphics are represented by exposure-response curves (smoothing plots) of daily average temperatures $\left(\operatorname{lag}_{0-1}\right)$ and daily number of health outcome data reported on a logarithmic scale. Curves represent the estimated mean percentage of change in daily health outcome data. This graphical representation allows to describe the current (1999-2008) and predicted variation in the shape of the exposure-response curve across cities, for the following near (2011-2030) and distant (2031-2050) 20-year periods, in relation to geographical characteristics.

In addition, city-specific annual short-term changes in temperaturerelated health outcome rates were also assessed. Annual rates (\%) were calculated by adding both the health outcome changes predicted per $1{ }^{\circ} \mathrm{C}$ decrease below and increase above the estimated temperature threshold, with respect to the base period (1999-2008), assessed for the following near and distant 20 -year periods. A positive annual temperature-related health outcome rate occurs when: a) both mortality (or hospitalization) changes predicted for cold and heat conditions are positive (overall mortality/hospitalization increase); b) the negative mortality (or hospitalization) change predicted for cold (or heat) is too slight to offset the substantial positive mortality (or hospitalization) change predicted for heat (or cold). The opposite situation occurs for negative annual rates.

\section{Results}

\subsection{Descriptive analysis}

For each of the three city-specific geographical areas, time-series of daily average temperatures and their spline-smoothed profiles are plotted in Fig. 1 . The highest mean daily temperature range, $12.1^{\circ} \mathrm{C}$, was observed on inland hill cities, followed by the inland plain, with $11.1^{\circ} \mathrm{C}$, while the lowest value, $9.9^{\circ} \mathrm{C}$, occurred on coastal plain cities. Highly significant seasonal fluctuations in health outcome data and temperatures were observed during the 10-year period in all geographical areas (Table 1). Mortality and hospitalizations generally reached the highest peaks during winter and spring respectively in all geographical areas. The summer was the season with commonly the lowest mortality and morbidity peaks. During the 10 -year study period, the average number of mortality and morbidity events obviously followed the
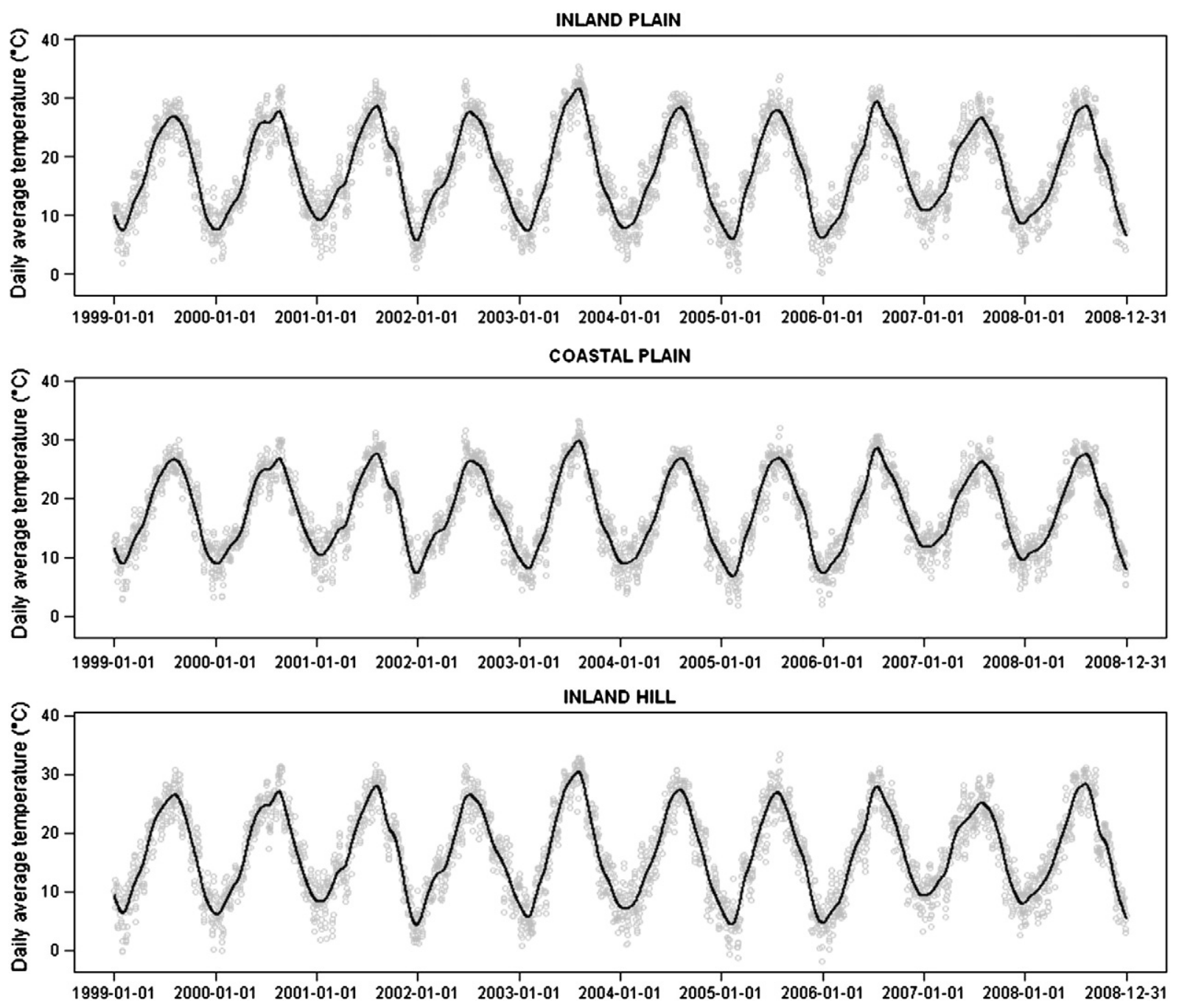

Fig. 1. Time-series of daily average temperatures $\left({ }^{\circ} \mathrm{C}\right)$ for geographical areas, $1999-2008$. Solid lines are smoothing splines. 
Table 1

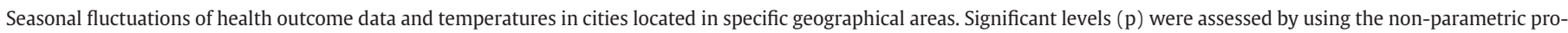

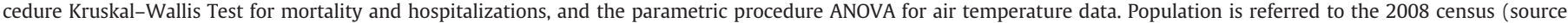
http://demo.istat.it/pop2008/index.html). Averages and standard deviation values are indicated.

\begin{tabular}{|c|c|c|c|c|c|}
\hline & \multicolumn{4}{|l|}{ Seasons } & \multirow[t]{2}{*}{$\mathrm{p}$} \\
\hline & Winter & Spring & Summer & Autumn & \\
\hline \multicolumn{6}{|c|}{ Inland plain (population: 722,959) } \\
\hline \multicolumn{6}{|l|}{ Mortality } \\
\hline$<65$ & $3.5 \pm 1.9$ & $3.1 \pm 1.7$ & $3.0 \pm 1.8$ & $3.0 \pm 1.7$ & $<0.0001$ \\
\hline $65-74$ & $4.7 \pm 2.2$ & $4.4 \pm 2.1$ & $3.9 \pm 2.1$ & $4.1 \pm 2.0$ & $<0.0001$ \\
\hline$>74$ & $20.5 \pm 5.1$ & $17.8 \pm 4.5$ & $16.1 \pm 4.7$ & $16.5 \pm 4.5$ & $<0.0001$ \\
\hline \multicolumn{6}{|l|}{ Hospitalizations } \\
\hline$<65$ & $178.1 \pm 60.6$ & $185.6 \pm 60.1$ & $153.7 \pm 53.8$ & $179.4 \pm 55$ & $<0.0001$ \\
\hline $65-74$ & $66.7 \pm 24.0$ & $69.3 \pm 24.4$ & $54.6 \pm 21.1$ & $65.9 \pm 21.8$ & $<0.0001$ \\
\hline$>74$ & $107.1 \pm 25.9$ & $107.5 \pm 25.9$ & $90.6 \pm 23.5$ & $103.1 \pm 24.1$ & $<0.0001$ \\
\hline Temperature $\left({ }^{\circ} \mathrm{C}\right)$ & $9.0 \pm 3.0$ & $16.9 \pm 4.6$ & $26.7 \pm 3.1$ & $18.3 \pm 5.1$ & $<0.0001$ \\
\hline \multicolumn{6}{|c|}{ Coastal plain (population: 462,617 ) } \\
\hline \multicolumn{6}{|c|}{ Mortality } \\
\hline$<65$ & $2.3 \pm 1.6$ & $2.4 \pm 1.6$ & $2.4 \pm 1.6$ & $2.1 \pm 1.5$ & $<0.0001$ \\
\hline $65-74$ & $3.3 \pm 1.9$ & $3.1 \pm 1.8$ & $2.9 \pm 1.7$ & $2.8 \pm 1.7$ & $<0.0001$ \\
\hline$>74$ & $12.6 \pm 3.8$ & $11.1 \pm 3.6$ & $10.4 \pm 3.7$ & $10.7 \pm 3.4$ & $<0.0001$ \\
\hline \multicolumn{6}{|l|}{ Hospitalizations } \\
\hline$<65$ & $137.6 \pm 48$ & $142.2 \pm 48.7$ & $122.3 \pm 38.4$ & $136.2 \pm 42.3$ & $<0.0001$ \\
\hline $65-74$ & $55.8 \pm 20.5$ & $57.9 \pm 21.0$ & $49.1 \pm 17.5$ & $55.7 \pm 19.3$ & $<0.0001$ \\
\hline$>74$ & $76.6 \pm 19.0$ & $76.6 \pm 18.8$ & $67.9 \pm 16.5$ & $74.1 \pm 17.5$ & $<0.0001$ \\
\hline Temperature $\left({ }^{\circ} \mathrm{C}\right)$ & $10.1 \pm 2.8$ & $16.5 \pm 4.0$ & $25.8 \pm 2.6$ & $18.8 \pm 4.4$ & $<0.0001$ \\
\hline \multicolumn{6}{|c|}{ Inland hill (population: 151,374 ) } \\
\hline \multicolumn{6}{|c|}{ Mortality } \\
\hline$<65$ & $0.9 \pm 0.9$ & $0.8 \pm 0.9$ & $0.7 \pm 0.9$ & $0.9 \pm 0.9$ & $<0.001$ \\
\hline $65-74$ & $1.3 \pm 1.2$ & $1.2 \pm 1.2$ & $1.1 \pm 1.1$ & $1.1 \pm 1.1$ & $<0.01$ \\
\hline$>74$ & $5.4 \pm 2.4$ & $4.7 \pm 2.2$ & $4.3 \pm 2.1$ & $4.4 \pm 2.1$ & $<0.0001$ \\
\hline \multicolumn{6}{|l|}{ Hospitalizations } \\
\hline$<65$ & $51.0 \pm 20.1$ & $53.7 \pm 20.3$ & $45.6 \pm 16.7$ & $51.2 \pm 17.1$ & $<0.0001$ \\
\hline $65-74$ & $20.3 \pm 8.9$ & $21.3 \pm 9.1$ & $18.2 \pm 7.9$ & $20.3 \pm 8$ & $<0.0001$ \\
\hline$>74$ & $28.8 \pm 8.6$ & $29.2 \pm 8.9$ & $25.4 \pm 8.1$ & $27.8 \pm 7.8$ & $<0.0001$ \\
\hline Temperature $\left({ }^{\circ} \mathrm{C}\right)$ & $7.9 \pm 3.1$ & $15.9 \pm 4.7$ & $25.9 \pm 3.2$ & $17.1 \pm 5.0$ & $<0.0001$ \\
\hline
\end{tabular}

geographical distribution of the population density: the highest average numbers of health outcome data were observed in all seasons and for all the age groups in the inland plain cities, followed by the coastal plain and the inland hill cities (Table 1). Temperatures were usually the lowest in the inland hill cities. Conversely, the highest average temperatures were observed in inland plain cities during spring and summer and in coastal plain cities during winter and autumn.

\subsection{Retrospective mortality/morbidity-temperature relationships}

The summarized results relating to the effect of cold and heat on mortality/morbidity are reported in Tables 2 and 3 respectively. The estimated temperature thresholds where mortality and morbidity were at their minimum were often found to be higher in the elderly (aged 65-74) and very elderly $(\geq 75)$ than in general adults $(<65)$. Mortality showed substantially higher threshold values than those observed for morbidity. Coastal plain cities showed the highest threshold and percentile values.

With regard to the impact of cold conditions (Table 2), significant cumulative cold effects were only observed for mortality of the elderly in the inland and coastal plain and for mortality of the very elderly in the coastal plain. An immediate but slight cold effect at the peak lag (peak lag $=0$ ) was observed for mortality of the elderly. Conversely, the lag at which the cold effect on mortality of the very elderly was greatest was limited to 5-7 days after cold exposure (See Supplementary material, online Fig. 3).

No significant cumulative cold effects (Table 2) were observed when morbidity (hospitalizations) was considered. Furthermore, a delayed cold effect at the peak lag was always observed: hospitalizations of general adults and the elderly were observed about three or four weeks after cold exposure; increased hospitalizations of the very elderly were slightly delayed (three days after the cold exposure). In addition, cold effects on hospitalizations of general adults and the elderly at the peak lag were always greater than those observed for mortality; conversely, the effects on hospitalizations of the very elderly were equal to or lower than those for mortality.

Regarding the impact of heat (Table 3), significant cumulative heat effects were observed for mortality of the elderly in the inland and coastal plain and for mortality of the very elderly in all geographical areas. Heat effects on mortality were always greater in coastal cities than inland ones and were substantially greater than those observed for the cold effect. However, it should be considered that the number of days above critical temperature thresholds for mortality (heat effect, Table 3) was substantially lower than that observed below thresholds (cold effect, Table 2). The heat effect on mortality was mostly immediate in all geographical areas and the greatest at lag 0 . The graphical representation of distributed lag curves for heat effects on mortality changes of the very elderly showed significant differences between coastal cities and inland ones starting from the day of exposure (lag 0) until lag 5 (Fig. 2). Furthermore, clear harvesting effects were evident from lag 8 to lag 16 in coastal plain cities and from lag 9 to 12 on those of the inland plain. Conversely, no harvesting effects were observed on inland hill cities.

No significant cumulative heat effects (Table 3) were observed when hospital admissions were considered. Moreover, cumulative heat effects were always negative. Contrary to the cold effect on hospitalizations, a general immediate heat effect (peak lag $=0$ ) was observed. Furthermore, the effects at peak lag were always lower than those observed for mortality.

\subsection{Future city-specific health risk estimations based on climatologic scenarios}

The predicted temperature changes, related to the baseline period (1999-2008), for the two 20-year A1B scenarios centered on 2020 and 2040 are indicated in Fig. 3. In particular, the average air temperature 
Table 2

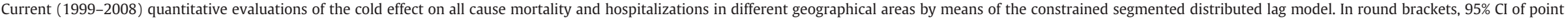
estimates is indicated. In bold, significant cumulative cold effects are indicated.

\begin{tabular}{|c|c|c|c|c|c|c|c|c|c|c|c|}
\hline \multirow{2}{*}{\multicolumn{2}{|c|}{$\begin{array}{l}\text { Geographical areas } \\
\text { and health outcomes } \\
\text { stratified by age }\end{array}$}} & \multicolumn{10}{|c|}{ Cold effect: \% change in mortality/morbidity events per $1{ }^{\circ} \mathrm{C}$ decrease in temperature below the identified threshold } \\
\hline & & \multicolumn{5}{|l|}{ All cause mortality } & \multicolumn{5}{|c|}{ All cause hospitalizations } \\
\hline & & $\begin{array}{l}\text { Estimated threshold } \\
\left({ }^{\circ} \mathrm{C}\right) \text { [percentile] }\end{array}$ & $\begin{array}{l}\text { N. of days below } \\
\text { threshold }\end{array}$ & Cumulative effect & Peak lag & Effect at peak lag & $\begin{array}{l}\text { Estimated threshold } \\
\left({ }^{\circ} \mathrm{C}\right) \text { [percentile] }\end{array}$ & $\begin{array}{l}\text { N. of days below } \\
\text { threshold }\end{array}$ & Cumulative effect & Peak lag & Effect at peak lag \\
\hline \multirow{3}{*}{ Inland plain } & $<65$ & $24.9[78]$ & 2871 & 1.05 ( -0.37 to 1.73$)$ & 0 & 0.08 ( -0.01 to 0.12$)$ & $12.3[29]$ & 1053 & $0.44(-2.83$ to 3.70$)$ & 23 & $0.41(0.30$ to 0.51$)$ \\
\hline & $65-74$ & $25.5[81]$ & 2963 & $1.29(0.14$ to 2.44$)$ & 0 & $0.04(0.01$ to 0.10$)$ & $13.1[32]$ & 1172 & $0.70(-3.82$ to 5.22$)$ & 18 & $0.40(0.26$ to 0.54$)$ \\
\hline & $\geq 75$ & $26.0[83]$ & 3038 & $2.04(-1.73$ to 5.81$)$ & 7 & $0.22(0.09$ to 0.34$)$ & 12.9 [31] & 1145 & $1.27(-1.69$ to 4.23$)$ & 3 & $0.22(0.10$ to 0.33$)$ \\
\hline \multirow[t]{3}{*}{ Coastal plain } & $<65$ & $24.5[80]$ & 2910 & $0.70(-0.04$ to 1.44$)$ & 0 & $0.04(-0.00$ to 0.09$)$ & $13.8[33]$ & 1215 & $0.12(-3.23$ to 3.48$)$ & 18 & 0.45 (0.35 to 0.55$)$ \\
\hline & $65-74$ & 27.4 [92] & 3366 & 0.84 (0.17 to 1.15$)$ & 0 & $0.06(0.01$ to 0.10$)$ & $15.7[43]$ & 1553 & 0.55 ( -3.86 to 4.97$)$ & 18 & 0.33 (0.18 to 0.48$)$ \\
\hline & $\geq 75$ & $26.7[89]$ & 3265 & $2.27(0.17$ to 4.93$)$ & 5 & $0.36(0.23$ to 0.48$)$ & $11.4[20]$ & 719 & 0.01 ( -1.79 to 1.73$)$ & 3 & 0.18 (0.03 to 0.33$)$ \\
\hline \multirow[t]{3}{*}{ Inland hill } & $<65$ & $23.9[80]$ & 2884 & $-0.00(-0.00$ to 0.00$)$ & 7 & $0.00(-0.00$ to 0.00$)$ & $9.5[21]$ & 753 & $1.58(-3.80$ to 6.97$)$ & 30 & $0.52(0.23$ to 0.81$)$ \\
\hline & $65-74$ & $25.3[84]$ & 3078 & $0.82(-0.29$ to 1.92$)$ & 0 & $0.06(-0.01$ to 0.14$)$ & $11.3[29]$ & 1063 & $0.45(-5.39$ to 6.28$)$ & 24 & $0.33(0.17$ to 0.50$)$ \\
\hline & $\geq 75$ & $25.4[85]$ & 3091 & $2.42(-1.21$ to 6.05$)$ & 6 & $0.38(0.26$ to 0.51$)$ & $11.4[29]$ & 1077 & $0.73(-2.83$ to 4.30$)$ & 3 & $0.24(0.07$ to 0.41$)$ \\
\hline
\end{tabular}

Table 3

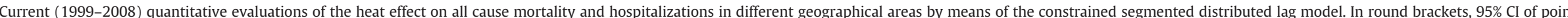
estimates is indicated. In bold, significant cumulative heat effects are indicated.

\begin{tabular}{|c|c|c|c|c|c|c|c|c|c|c|c|}
\hline \multirow{3}{*}{\multicolumn{2}{|c|}{$\begin{array}{l}\text { Geographical } \\
\text { areas and health } \\
\text { outcomes stratified } \\
\text { by age }\end{array}$}} & \multicolumn{10}{|c|}{ Heat effect: \% change in mortality/morbidity events per $1{ }^{\circ} \mathrm{C}$ increase in temperature above the identified threshold } \\
\hline & & \multicolumn{5}{|l|}{ All cause mortality } & \multicolumn{5}{|c|}{ All cause hospitalizations } \\
\hline & & $\begin{array}{l}\text { Estimated threshold } \\
\left({ }^{\circ} \mathrm{C}\right) \text { [percentile] }\end{array}$ & $\begin{array}{l}\text { N. of days above } \\
\text { threshold }\end{array}$ & Cumulative effect & Peak lag & Effect at peak lag & $\begin{array}{l}\text { Estimated threshold } \\
\left({ }^{\circ} \mathrm{C}\right) \text { [percentile] }\end{array}$ & $\begin{array}{l}\text { N. of days above } \\
\text { threshold }\end{array}$ & Cumulative effect & Peak lag & Effect at peak lag \\
\hline \multirow[t]{3}{*}{ Inland plain } & $<65$ & $24.9[78]$ & 782 & $2.08(-0.40$ to 4.57$)$ & 0 & 1.38 (0.58 to 2.17$)$ & $12.3[29]$ & 2600 & $-0.35(-1.64$ to 0.93$)$ & 0 & $0.08(-0.02$ to 0.18$)$ \\
\hline & $65-74$ & $25.5[81]$ & 690 & $2.10(0.07$ to 4.13$)$ & 0 & $1.50(0.70$ to 2.30$)$ & $13.1[32]$ & 2481 & $-0.59(-2.16$ to 0.99$)$ & 0 & $0.03(-0.05$ to 0.14$)$ \\
\hline & $\geq 75$ & $26.0[83]$ & 615 & $6.22(0.11$ to 12.71$)$ & 0 & $2.24(1.17$ to 3.31$)$ & $12.9[31]$ & 2508 & $-0.60(-1.60$ to 0.40$)$ & 0 & $0.21(0.09$ to 0.33$)$ \\
\hline \multirow[t]{3}{*}{ Coastal plain } & $<65$ & $24.5[80]$ & 743 & $1.51(-3.93$ to 6.95$)$ & 0 & 1.64 (0.51 to 2.77$)$ & $13.8[33]$ & 2438 & $-0.65(-1.98$ to 0.67$)$ & 0 & $0.21(-0.02$ to 0.30$)$ \\
\hline & $65-74$ & 27.4 [92] & 287 & 7.76 (1.41 to 14.11$)$ & 0 & $4.26(2.04$ to 6.47$)$ & $15.7[43]$ & 2100 & $-0.65(-2.22$ to 0.92$)$ & 0 & $0.16(-0.01$ to 0.33$)$ \\
\hline & $\geq 75$ & $26.7[89]$ & 388 & 15.97 (7.43 to 24.51 ) & 0 & 4.33 (3.40 to 5.26$)$ & $11.4[20]$ & 2934 & $-0.58(-1.46$ to 0.31$)$ & 0 & $0.08(0.01$ to 0.15$)$ \\
\hline \multirow{3}{*}{ Inland hill } & $<65$ & $23.9[80]$ & 769 & $-0.01(-3.94$ to 3.92$)$ & 0 & $1.48(0.58$ to 2.37$)$ & $9.5[21]$ & 2900 & $-0.23(-1.55$ to 1.09$)$ & 0 & $0.06(-0.03$ to 0.15$)$ \\
\hline & $65-74$ & $25.3[84]$ & 575 & $-0.61(-8.93$ to 7.72$)$ & 0 & $0.67(-0.04$ to 1.38$)$ & $11.3[29]$ & 2590 & $-0.20(-1.46$ to 1.06$)$ & 0 & $0.07(-0.09$ to 0.23$)$ \\
\hline & $\geq 75$ & $25.4[85]$ & 562 & 5.49 (1.39 to 9.58$)$ & 0 & $2.23(1.36$ to 3.10$)$ & 11.4 [29] & 2576 & $-0.32(-2.20$ to 1.56$)$ & 0 & $0.15(0.02$ to 0.29$)$ \\
\hline
\end{tabular}




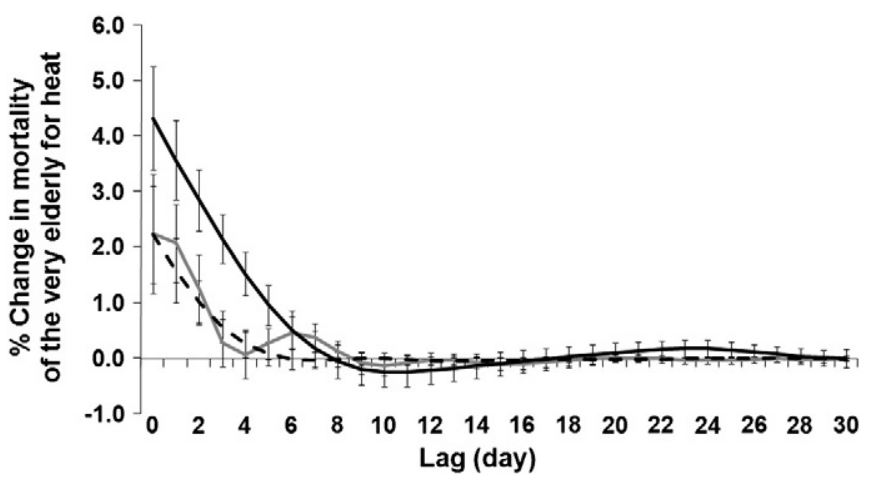

Fig. 2. Estimated distributed lag curves (\% change in mortality of the very elderly) for heat effects in three geographical areas during the 1999-2008 period. Temperature thresholds are $26.7{ }^{\circ} \mathrm{C}$ ( 89 th percentile), $26.0{ }^{\circ} \mathrm{C}$ (83rd percentile) and $25.4{ }^{\circ} \mathrm{C}$ ( 85 th percentile) for the coastal plain (black continuous line), inland plain (gray continuous line) and inland hill (black broken line) cities respectively. Bars indicate the $95 \% \mathrm{CI}$ of point estimates.

predictions show an expected increases of $1.0{ }^{\circ} \mathrm{C}$ and $2.4{ }^{\circ} \mathrm{C}$ for the following near (2011-2030) and distant (2031-2050) 20-year periods respectively. Temperature changes are expected to be slightly higher on the coastal cities than on the inland ones. Seasons predicted to largely contribute to the whole annual temperature increase are winter and summer (Fig. 3): 65\% and 59\% during the 2020 and 2040 periods respectively.

Because the retrospective analysis showed that the temperature had the greatest and most significant impact on mortality in the very elderly ( $\geq 75$ ), the city-specific health risk estimation for the two 20-year periods of $\mathrm{A} 1 \mathrm{~B}$ temperature scenarios focused on this age bracket. The estimated temperature thresholds were on average higher in coastal plain cities (average value $26.4{ }^{\circ} \mathrm{C}$ ) than on the inland plain (average value $25.9{ }^{\circ} \mathrm{C}$ ) and hill (average value $24.0^{\circ} \mathrm{C}$ ) cities. The highest percentile values of the estimated temperatures were also found on the coastal plain, with values ranging from the 86th to the 90th percentile. The baseline mortality change, assessed over the 10-year period (1999-2008), was also always higher in coastal cities than inland ones. The predicted mortality changes of the very elderly caused by short-term (lag $\left.\operatorname{la}_{0-1}\right)$ cold conditions for future years showed different patterns among cities. In particular, half the cities showed an unexpected increase in mortality risk for both the following near (2011-2030) and distant (2031-2050) 20-year periods with respect

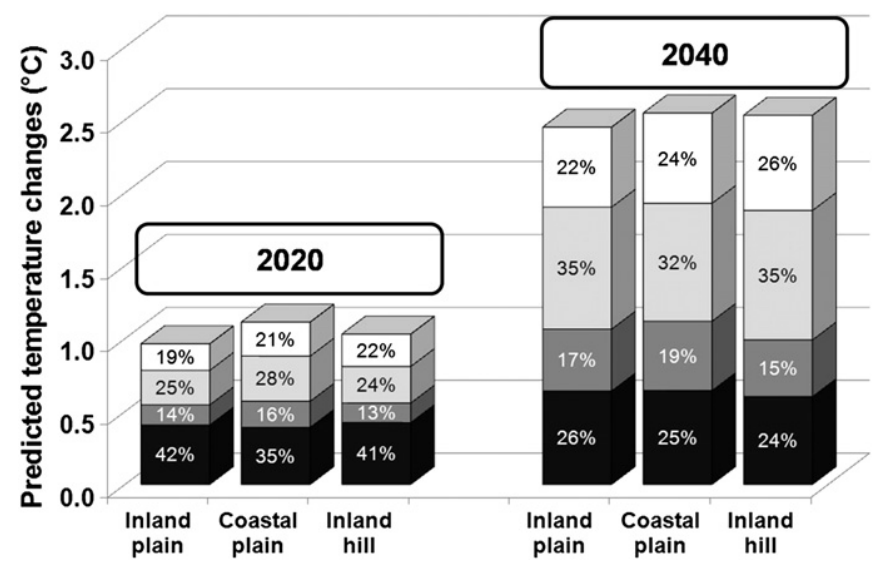

Fig. 3. Temperature changes predicted on cities located in specific geographical areas for the following near (for 2020: 2011-2030) and distant (for 2040: 2031-2050) 20-year periods, related to the baseline period (1999-2008), based on high-resolution city-specific climatologic A1B scenarios. The seasonal contribution to the annual average temperature change for each geographical area is expressed as percentage value: winter, spring, summer and autumn contributions are indicated by black, dark gray, light gray and white bars respectively. to the baseline period (1999-2008) (Table 4). The highest increases in short-term cold-related mortality are predicted in Arezzo and Pistoia, located in the inland hill and plain areas respectively. In these cases, gradual and slight increases in the very-elderly mortality risks with decreasing temperatures are expected during the 2020 and 2040 periods, with respect to the baseline period (Fig. 4). Conversely, other cities showed a typical decrease in the predicted short-term cold-related mortality, especially in coastal cities with Livorno being the only exception. In most coastal plain cities, during both 20 -year periods of 2020 and 2040, the very-elderly mortality risks tend to drop to zero with decreasing the average temperatures (Fig. 4).

With regard to the predicted short-term heat effect on the veryelderly mortality, as expected, most cities showed a greater predicted mortality change than that observed during the reference period, with only two exceptions that showed no mortality variation (Prato) or a decrease in the predicted heat-related mortality (Grosseto) for the following near (2011-2030) 20-year period (Table 4). However, increases in heat-related mortality were always observed in all cities in the following distant (2031-2050) 20-year period. The highest increases are predicted in coastal cities, which also showed the steepest curves of heat-related mortality and the highest mortality risk values for extremely high temperatures (Fig. 4).

In general, it was observed that the change in cold-related mortality is usually slight when compared to the change in heat-related mortality in the very elderly (Table 4 ). Therefore, the predicted reduction in the short-term cold-related mortality observed in several cities is expected to be too slight to offset the substantial predicted increase in the short-term heat-related mortality. The cities of Prato and Grosseto represent two exceptions which only show a general decrease in the predicted annual temperature-related mortality rate for the following near 20-year period (2011-2030) (Fig. 5). However, increased burdens of the heat-related mortality will be always expected for the following distant 20-year period (2031-2050) (Fig. 5).

\section{Discussion}

This study not only confirms several results obtained from previous studies analyzing the relationship between temperature and several human health outcomes, but also adds new findings that emphasize different geographical patterns of these relationships on a regional scale and provides predictions of future city-specific impact on human health due to climate change. Essentially, this work gives a chance to make a quantitative assessment of future health risks related to climate changes.

In detail, the main results of this study can be summarized in two sections:

1. Current impact of air temperature on human health:

- The cumulative impact of both cold and heat effects was only significant on mortality in the elderly (aged 65-74) and the very elderly $(\geq 75)$; conversely, no significant cumulative impact was observed on mortality in general adults $(<65)$ or any age-stratified morbidity events (hospitalizations).

- The heat impact on mortality was always immediate (peak lag $=0$ ), often followed by negative estimates (harvesting effect), and substantially greater than the cold effect.

- Both heat and cold effects on mortality were higher in coastal plain cities than inland cities.

2. Future health risk estimations based on climate-change scenarios:

- A slight unexpected increase in short-term cold-related mortality in the very elderly with respect to the baseline period (1999-2008) is predicted for the following years in half the cities considered.

- Most cities also showed an extensive predicted increase in shortterm heat-related mortality of the very elderly that was always greater than the predicted change in short-term cold-related mortality. 
Table 4

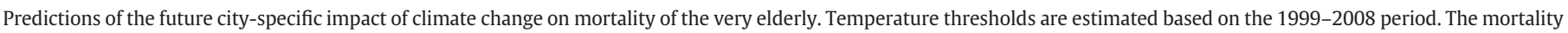

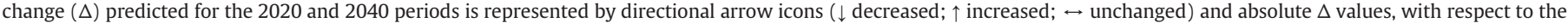
baseline period. In round brackets, $95 \% \mathrm{CI}$ of point estimates is indicated.

\begin{tabular}{|c|c|c|c|c|c|c|c|c|c|c|c|}
\hline \multirow{3}{*}{$\begin{array}{l}\text { City-specific } \\
\text { geographical } \\
\text { areas }\end{array}$} & \multirow{3}{*}{$\begin{array}{l}\text { Estimated temperature } \\
\text { thresholds at lago-1 } \\
\text { [percentile] }\end{array}$} & \multicolumn{5}{|c|}{$\begin{array}{l}\% \text { Change in mortality per } 1{ }^{\circ} \mathrm{C} \text { decrease below } \\
\text { the estimated temperature threshold }\end{array}$} & \multicolumn{5}{|c|}{$\begin{array}{l}\text { \% Change in mortality per } 1{ }^{\circ} \mathrm{C} \text { increase above the } \\
\text { estimated temperature threshold }\end{array}$} \\
\hline & & \multirow[t]{2}{*}{ Base } & \multirow{2}{*}{$\begin{array}{l}2020 \\
\text { Mortality } \\
\text { predicted }\end{array}$} & \multirow[t]{2}{*}{$\Delta$} & \multirow{2}{*}{$\begin{array}{l}2040 \\
\text { Mortality } \\
\text { predicted }\end{array}$} & \multirow[t]{2}{*}{$\Delta$} & \multirow[t]{2}{*}{ Base } & \multirow{2}{*}{$\begin{array}{l}2020 \\
\text { Mortality } \\
\text { predicted }\end{array}$} & \multirow[t]{2}{*}{$\Delta$} & \multirow{2}{*}{$\begin{array}{l}2040 \\
\text { Mortality } \\
\text { predicted }\end{array}$} & \multirow[t]{2}{*}{$\Delta$} \\
\hline & & & & & & & & & & & \\
\hline \multicolumn{12}{|l|}{ Inland plain } \\
\hline Florence & $26.7[83]$ & 0.9 & $0.8(0.6-1.0)$ & $\downarrow 0.1$ & $0.7(0.5-0.9)$ & $\downarrow 0.2$ & 7.6 & $9.1(7.8-10.6)$ & $\uparrow 1.5$ & $10.3(9.3-11.3)$ & $\uparrow 2.7$ \\
\hline Prato & $26.5[82]$ & 0.9 & $0.5(0.2-0.8)$ & $\downarrow 0.4$ & $0.5(0.2-0.9)$ & $\downarrow 0.4$ & 5.1 & $5.1(3.4-7.3)$ & $\leftrightarrow 0.0$ & $7.5(4.4-5.9)$ & $\uparrow 2.4$ \\
\hline Pistoia & $24.5[78]$ & 0.7 & $1.2(0.9-1.6)$ & $\uparrow 0.5$ & $1.6(1.0-2.2)$ & $\uparrow 0.9$ & 4.6 & $6.9(4.4-10.1)$ & $\uparrow 2.3$ & $6.2(4.5-8.3)$ & $\uparrow 1.6$ \\
\hline Lucca & $25.9[82]$ & 1.4 & $1.6(1.1-2.3)$ & $\uparrow 0.2$ & $1.5(1.1-2.0)$ & $\uparrow 0.1$ & 8.8 & $10.2(7.3-13.8)$ & $\uparrow 1.4$ & $12.2(9.2-15.7)$ & $\uparrow 3.4$ \\
\hline Average & $25.9[81]$ & 1.0 & $1.1(0.7-1.4)$ & $\uparrow 0.1$ & $1.1(0.7-1.5)$ & $\uparrow 0.1$ & 6.5 & $7.8(5.7-10.5)$ & $\uparrow 1.3$ & $9.0(6.9-10.3)$ & $\uparrow 2.5$ \\
\hline \multicolumn{12}{|l|}{ Coastal plain } \\
\hline Massa-Carrara & $25.5[90]$ & 1.0 & $0.6(0.1-1.1)$ & $\downarrow 0.4$ & $0.6(0.2-1.1)$ & $\downarrow 0.4$ & 18.1 & $24.1(20.4-28.2)$ & $\uparrow 6.0$ & $29.9(26.1-34.1)$ & $\uparrow 11.8$ \\
\hline Livorno & $26.0[86]$ & 2.2 & $2.6(2.2-3.0)$ & $\uparrow 0.4$ & $2.5(1.9-3.1)$ & $\uparrow 0.3$ & 17.0 & $22.1(18.4-26.4)$ & $\uparrow 5.1$ & $24.3(20.9-28.1)$ & $\uparrow 7.3$ \\
\hline Pisa & $26.9[90]$ & 1.7 & $0.4(0.1-0.8)$ & $\downarrow 1.3$ & $0.5(0.1-1.0)$ & $\downarrow 1.2$ & 17.8 & $20.8(16.2-26.3)$ & $\uparrow 3.0$ & $23.7(20.7-27.1)$ & $\uparrow 5.9$ \\
\hline Grosseto & $27.1[87]$ & 1.4 & $0.2(-0.2-0.6)$ & $\downarrow 1.2$ & $0.2(-0.3-0.7)$ & $\downarrow 1.2$ & 8.9 & $4.3(2.4-6.5)$ & $\downarrow 4.6$ & $10.4(7.8-13.4)$ & $\uparrow 1.5$ \\
\hline Average & $26.4[88]$ & 1.6 & $1.0(0.6-1.4)$ & $\downarrow 0.6$ & $1.0(0.5-1.5)$ & $\downarrow 0.6$ & 15.5 & $17.9(14.4-21.9)$ & $\uparrow 2.4$ & $22.0(18.9-25.7)$ & $\uparrow 6.5$ \\
\hline \multicolumn{12}{|l|}{ Inland hill } \\
\hline Siena & $24.9[84]$ & 0.7 & $0.7(0.4-1.1)$ & $\leftrightarrow 0.0$ & $0.9(0.6-1.3)$ & $\uparrow 0.2$ & 4.7 & $5.5(3.2-8.3)$ & $\uparrow 0.8$ & $6.7(4.6-9.3)$ & $\uparrow 2.0$ \\
\hline Arezzo & $23.0[75]$ & 1.6 & $2.4(1.6-3.3)$ & $\uparrow 0.8$ & $2.4(1.7-3.1)$ & $\uparrow 0.8$ & 4.0 & $6.6(4.6-8.9)$ & $\uparrow 2.6$ & $4.1(2.6-6.0)$ & $\uparrow 0.1$ \\
\hline Average & $24.0[80]$ & 1.2 & $1.6(1.0-2.2)$ & $\uparrow 0.4$ & $1.7(1.2-2.2)$ & $\uparrow 0.5$ & 4.4 & $6.1(3.9-8.6)$ & $\uparrow 1.7$ & $5.5(3.6-7.7)$ & $\uparrow 1.1$ \\
\hline
\end{tabular}

1999-2008
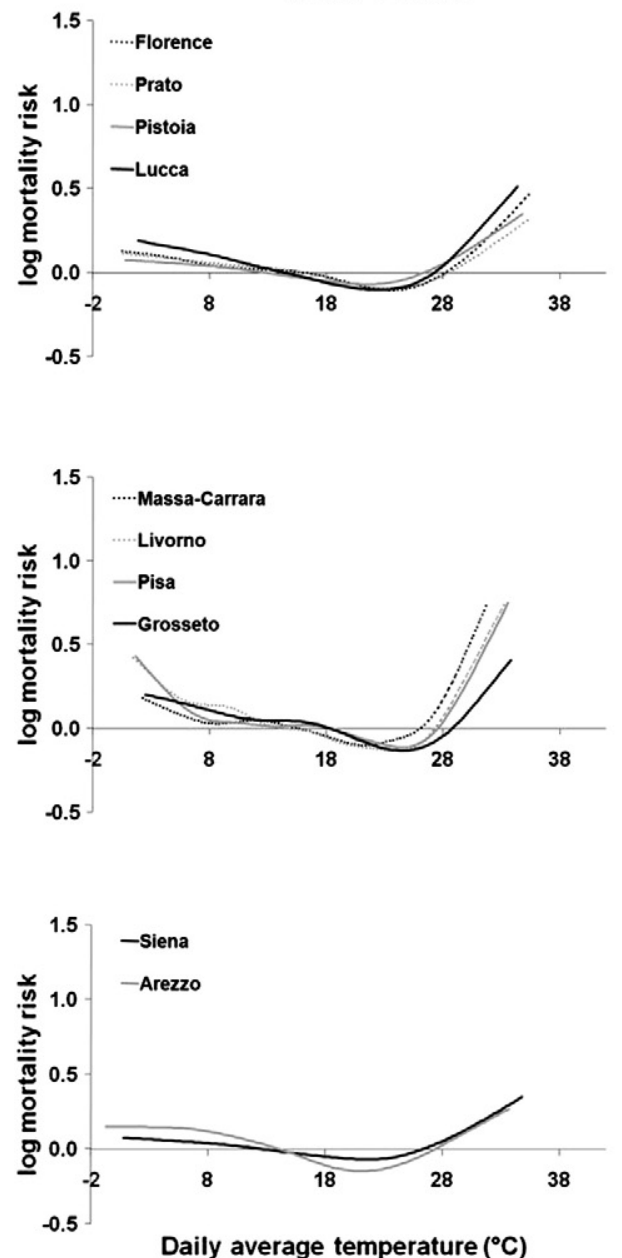

\section{INLAND PLAIN}

2020

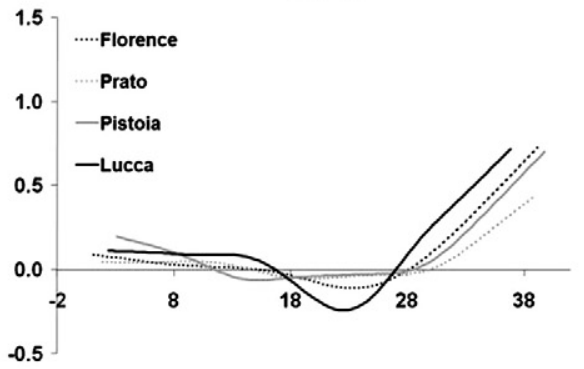

COASTAL PLAIN

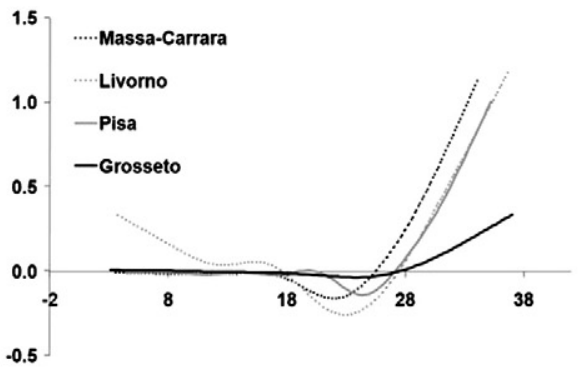

INLAND HILL
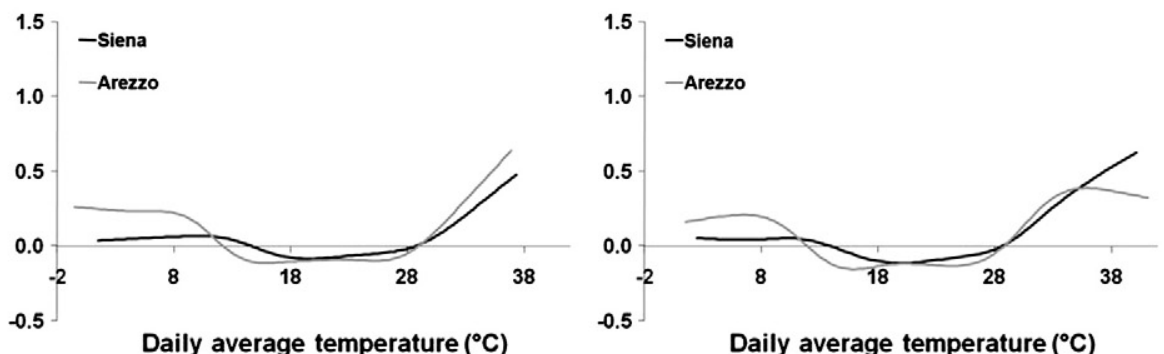

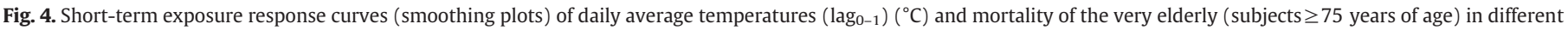

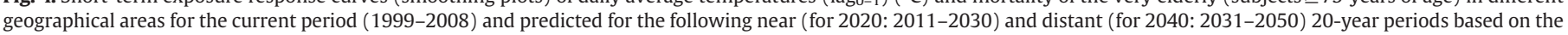
A1B climatologic scenario. 


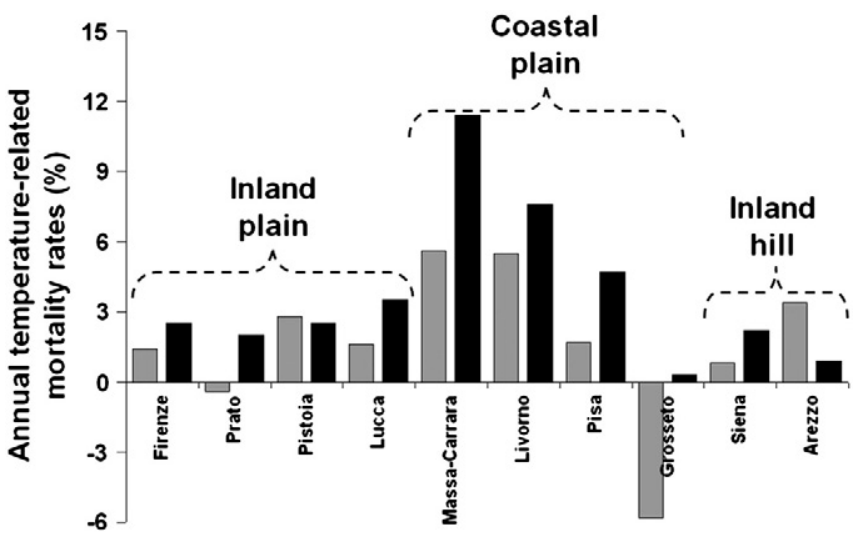

Fig. 5. Annual temperature-related mortality rates (\%) of the very elderly (subjects $\geq$ 75 years of age) predicted for the following near (gray bars) (for 2020: 2011-2030) and distant (black bars) (for 2040: 2031-2050) 20-year periods based on the high-resolution A1B climatologic scenario.

- The predicted annual temperature-related mortality rates are prevalently positive in most cities for the following near 20 -year period (2011-2030) and are always positive in all cities for the following distant 20-year period (2031-2050), reaching the highest vales in the coastal plain cities.

\subsection{Current impact of air temperature on human health}

In compliance with previous studies (Kovats et al., 2004; Linares and Díaz, 2008; Mastrangelo et al., 2006), our results show a differentiated pattern between mortality and hospital admissions in the case of low/high temperature conditions and confirm a greater impact of the temperature (especially high temperatures) on mortality than on morbidity events. Furthermore, our results also show a negative cumulative effect (over a lag-period of 30 days) of heat on hospitalizations, which means a general decrease in total hospital admissions when over-threshold temperatures occur. The contrast between mortality and hospital admissions represents a remarkable finding in agreement with a recent study (Williams et al., 2012) where the authors also evidenced a decrease in total hospital admissions on heat-wave days. The discrepancy between increased mortality and decreased hospitalizations might be explained by the fact that heatrelated mortality can occur rapidly, with a short-time interval between exposure to high temperatures and subsequent death. For this reason it is plausible to hypothesize that patients die before they can be admitted to hospital (Kovats and Hajat, 2008) and this risk is particularly high in people aged $>65$. In a recent review (Ye et al., 2012) based on the epidemiological evidence of the impact of temperature on morbidity, the authors stated that the majority of studies reported detrimental effects of heat at short lags and longer cold effects up to a 2-3 week lag. However, it is well known that the impact of temperature on morbidity is less certain than the temperaturemortality association, and a great heterogeneity of results has been observed across the studies. In this study no significant cumulative effects (over a period of 30 days) on hospitalizations of either heat or cold conditions were observed, however, a general immediate heat effect (peak lag $=0$ ) and a delayed cold effect at the peak lag (generally up to 2-3 weeks) were always observed.

This study also confirmed the fact that changes in the average temperatures have a larger impact on mortality in the elderly population than in general adults, as described in a recent review (Yu et al., 2011). The reason might be attributed to a diminished or delayed physiological ability of the elderly population to maintain their core temperature within safe and acceptable limits, and also because of the worsening of other factors such as living conditions, family and/ or social support and the ability to access medical-care systems.
It is interesting to note that the higher temperature thresholds in the elderly population ( $\geq 65$ years) compared to general adults $(<65$ years) observed in this study are partially in contrast with previous findings from another European study (Laaidi et al., 2006): the authors found a decreasing level of the thermal optimum with the increase in age in the City of Paris, where the elderly showed a poorer adaptation to heat. Conversely, and in line with our results, the authors also evidenced a more prominent thermal optimum for older people in other cities with different geographical locations.

The highest temperature thresholds observed for the elderly in this study might be attributed to an improved adaptation of the elderly population to heat, especially thanks to the preventive measures, information plans on heat effects on human health, and the setting up of city-specific heat health warning systems (HHWS) with detailed interventions for safeguarding the health of the elderly. In particular, in a recent study carried out over the Florentine area (Morabito et al., 2012), a temporal modification of the heat-related risk in elderly people was detected by comparing previous (1999-2002) and subsequent (2004-2007) periods to the summer of 2003, when a regional HHWS was set up: exposure-response curves between mortality and apparent temperatures were clearly steepest for extreme values and with more evident critical apparent temperature thresholds during the 1999-2002 period than the 2004-2007 period. Furthermore, the change in mortality of very elderly people $(\geq 75)$ for a $1{ }^{\circ} \mathrm{C}$ increase in apparent temperature was significantly higher (often more than double) during the 4-year period without the HHWS (1999-2002) than during the 2004-2007 period when a local HHWS was set up.

Compared to populations living in cities at similar latitudes (McMichael et al., 2008), our results confirm the greater and more immediate $(\mathrm{lag}=0$ ) heat effect on the elderly population with respect to the delayed (lags up to 7 days) and more distributed cold effect. This pattern has already been evidenced in previous studies where the heat effects were mostly immediate while the cold effects were delayed by several weeks (Muggeo and Hajat, 2009). However, because in this study high percentile values of temperature thresholds for mortality were identified and, for this reason, the number of days below thresholds was substantially higher than that observed above thresholds, the cold effect on mortality was more distributed over time than the heat effect. This observation might be helpful to explain the highest number of deaths generally observed during the coldest season.

Furthermore, our study also confirmed the mortality displacement evidenced in coastal and inland plain cities. This phenomenon, called the "harvesting effect", occurs when a positive association at short lags is followed by a negative association at longer lags, which should suggest a mortality "deficit” (Muggeo, 2010).

The international ISOTHURM project on the effects of temperature on urban mortality (McMichael et al., 2008) in several European cities with geographical characteristics similar to the cities considered in this study gave interesting and comparable results. For example, for the city of Bucharest (70 $\mathrm{m}$ a.s.l.), characterized by a continental climate and latitude and altitude levels similar to the cities classified in this study as "inland plain", percentage increases were observed in total mortality equal to $0.85 \%$ and $3.30 \%$ below and above the temperature threshold respectively. These values are comparable with those observed in this study where the increase in mortality of the very elderly was on average $1.0 \%$ and $6.5 \%$ below and above the temperature threshold respectively. In another European city, Sofia (550 m a.s.l.), with geographical characteristics comparable with the cities classified in this study as "inland hill", percentage increases in total mortality of $0.93 \%$ and $2.88 \%$ below and above the temperature threshold respectively were observed (McMichael et al., 2008). In this study, the increase of mortality of the very elderly below the temperature threshold was on average $1.2 \%$, while the increase above the threshold was on average $4.4 \%$. The reason why, in this study, the average increase in mortality below/above cold/heat thresholds was higher than in the McMichael 
et al. (2008) study, is attributed to the fact that we investigated the mortality of more susceptible people, such as the very elderly. Furthermore, the ISOTHURM study also included air pollution as a potential confounder, but the impact of its inclusion on the temperature slopes was very slight.

Previous studies (Analitis et al., 2008; Laaidi et al., 2006; The Eurowinter Group, 1997) also evidenced a large-scale (at a continental or national level) geographical heterogeneity of temperaturerelated mortality and it is already known that excessive heat is more likely to increase the mortality risk in the coldest areas, while populations living in warmer regions tend to be more vulnerable to cold. Moreover, in another study (Keatinge et al., 2000b), the authors found that the cold-effect on mortality is particularly evident in regions where people have poor protection against cold. This study clearly shows that at a regional level (Central Italy), both heat and cold effects on mortality also reached the highest levels in the milder coastal plain cities. These cities showed higher average temperatures during winter and autumn and lower temperatures during summer than inland cities. These characteristic climate conditions (coastal climate), with typically low daily temperature ranges and little annual temperature variations, make the population living on the coast more susceptible and less adaptable to sudden temperature changes and extremes: the coastal cities showed the worst health situation when compared with the other cities with different geographical locations. It is also interesting to note that in the coldest cities considered in this study, the inland hill ones, no significant cold effects were found on health outcomes. In addition, significant heat effects were only seen on mortality when the very elderly were considered.

\subsection{Estimations of future health risks based on climate change scenarios}

While there are extensive retrospective investigations in literature regarding the association between severe meteorological conditions and health risks, publications estimating how climate change will affect populations through modeling approaches are less common and not decisive. Several studies reported a prevalent slight, but in some cases also marked, decrease in winter mortality in temperate countries as a consequence of climate change (Davis et al., 2004; Donaldson et al., 2001; Doyon et al., 2008; Kalkstein and Greene, 1997; Langford and Bentham, 1995). However, for the first time our study has reported that in half the cities a slight increase in short-term cold-related mortality in the very elderly, with respect to the base period (1999-2008), is expected for both the following near (2011-2030) and distant (2031-2050) 20-year periods, mainly in populations living in several inland cities. These cities are located in geographical areas where the coldest period of the year is generally cool and not very cold (the average daily air temperatures during winter range between $7.9{ }^{\circ} \mathrm{C}$ in inland hill cities and $9.0^{\circ} \mathrm{C}$ for inland plain cities), but where sudden temperature fluctuations and severe cold periods are not unusual. This is also backed up by the fact that the IPCC reported that climate warming entails a general increase in the average annual temperature for urban areas as well as an increasing probability of extreme meteorological events, such as heat waves and cold spells, ice storms and excessive rainfall (IPCC, 2007). Furthermore, it should also be noted that the predicted increase in average temperatures during the typical $\mathrm{cool} / \mathrm{cold}$ period of the year might also facilitate behavioral adaptations, such as not wearing sufficient winter clothing, infrequent use (especially in Mediterranean countries) of accessories such as gloves, scarves and hats, whilst also encouraging people to spend more time outdoors. These behavioral adaptations in turn might also influence the health risk of frail people (such as the very elderly) if sudden temperature changes occur. In these conditions, a typical winter temperature decrease, and not only an extreme event (such as cold spell or ice storm), might also significantly worsen the thermal perception of people surprised in outdoor environments while wearing inappropriate clothing. Previous authors reported that the increased weather variability, also predicted during winter by climate models, might result in significant cold-related consequences for humans (Conlon et al., 2011). However, a European study (The Eurowinter Group, 1997) clearly showed that correct clothing was reported to contribute to preventing excess winter mortality. Furthermore, in one of our previous studies (Morabito et al., 2008) we also demonstrated that during the coldest season of the year, a primary risk factor for mortality events, namely blood pressure, was higher on milder winter days than on colder ones.

Conversely, a general decrease in short-term cold-related mortality is expected for the coming years not only in coastal cities, which are generally characterized by infrequent temperature fluctuations, but also in two inland plain cities (Florence and Prato) characterized by the highest urban heat island effect. These results were in agreement with all previous studies where a decrease in winter mortality was predicted for future years (Davis et al., 2004; Donaldson et al., 2001; Doyon et al., 2008; Kalkstein and Greene, 1997; Langford and Bentham, 1995).

This study clearly shows a marked general increase predicted for short-term heat-related mortality in the very elderly in all geographical areas for the following near (2011-2030) and distant (2031-2050) 20 -year periods. It has been suggested that the increase in heatrelated mortality may be offset by the reduction in cold-related mortality as a result of global warming, but discrepancies exist among the magnitudes of these changes (Gosling et al., 2009). Several authors predicted decreased temperature-related mortality burdens (Guest et al., 1999; Keatinge et al., 2000a): the mortality decrease in winter will be greater than the mortality increase in summer. However, most studies showed increased burdens of heat-related mortality that will not be offset by the decreased cold-related mortality (Doyon et al., 2008; El-Zein et al., 2004; Kalkstein and Greene, 1997; Knowlton et al., 2007; Medina-Ramón and Schwartz, 2007). A recent Canadian study (Martin et al., 2011) also reported different temperaturerelated mortality burdens among cities: decreased burdens were predicted in 11 cities and increased burdens were observed in 4 other cities. However, the study was not stratified by age.

The study clearly showed how the annual temperature-related mortality rates of the very elderly will prevalently increase in almost all cities for the 2011-2030 period (with only two exceptions showing decreased burdens) and will always increase in all cities during the 2031-2050 period. These increased burdens of mortality in the elderly are expected to be particularly high in mild coastal plain cities and less marked in the inland cities. Indeed, it is well known that tolerance to temperature extremes varies regionally according to the population and its preparedness for heat or cold conditions, and also according to the local average temperatures and frequency of extreme temperatures (McMichael et al., 1996). It is plausible to hypothesize that populations living in coastal plain cities are more susceptible to temperature changes and extremes due to being used to milder climate conditions with low daily and annual temperature variations and where extremely high temperatures are uncommon or occur infrequently. This is in agreement with the fact that periods with the highest temperature-mortality risk in temperate regions, especially those with generally mild weather conditions, are the ones characterized by infrequent temperature fluctuations (McGeehin and Mirabelli, 2001).

Furthermore, according to the most recent world estimates, the elderly population is predicted to increase significantly, and also in Italy a sharp rise in the number of people aged 65 and over is predicted for the coming years: by the year $2050,34.6 \%$ of the population will be over the age of 65 years (De Luca d'Alessandro et al., 2011), against approximately $20 \%$ reported in the 2011 census (http://demo.istat.it/ pop2011/index.html). With reference to the two 20-year periods considered in this study, on the basis of the 2010 revision of the World Population Prospects (United Nations, Department of Economic and Social Affairs, Population Division, 2011), $17.6 \%$ and $23.7 \%$ of the 
very elderly population (people aged 75 and over) are predicted in Italy for the 2020 and 2040 years respectively, against about $10.0 \%$ reported in the 2011 census (http://demo.istat.it/pop2011/index. html).

Moreover, the IPCC (2007) stated that extreme events, such as the European heat-wave of 2003, would be more common in future warmer climates. Because these conditions will have important implications for health, there is a pressing need to quantify the overall risk of death associated with temperature changes among the elderly (Yu et al., 2011). This information is useful for developing efficient preventive strategies, such as enhancement of medical care, an increase in the use of air-conditioning to contrast heat stress, and the development of weather (heat/cold) health warning systems specifically for susceptible people. Recent studies (Fouillet et al., 2008; Morabito et al., 2012) clearly confirm that effective preventive policies might also contribute towards changing the vulnerability of people at the highest risk.

\subsection{Strengths and limitations}

The major strength of this study is the application of such a robust statistical method as the "constrained segmented distributed lag model" (Muggeo, 2010) which allows for simultaneously taking into account the non-linearity effect of temperature on health outcome data and the distributed lag effect of the temperature exposure. This approach belongs to the family of the distributed lag models (Gasparrini, 2011) and represents the state-of-the-art of studies on environmental epidemiology. In addition, all the analyses were controlled for important confounders, including the seasonal effect. Several authors (Doyon et al., 2008) clearly demonstrated that a model adjusted for this effect is essential if mortality due to climate change is not to be confused with mortality due to seasonal factors, such as winter flu epidemics.

Another strength of this study is the use of a uniform and homogeneous spatially-distributed meteorological dataset of modeled daily average air temperatures with data not lacking when compared with data based on observations coming from weather stations. Furthermore, the arbitrary selection of a single point-source weather station may not be representative of the average temperature on an urban scale. In addition, the use of modeled weather data ensures readily replicable and comparable studies. In this study the use of the daily average temperature as an exposure indicator for both heat and cold conditions offers several advantages, and particularly the fact that this meteorological parameter, taking into consideration the whole day and night, generally provides more easily interpreted results within a policy context (Anderson and Bell, 2009).

However, this study has several limitations. The first source of uncertainty is represented by the goodness of estimates of future health trends based on city-specific climate scenarios. Although climate models have been greatly enhanced over recent years and have become progressively more sophisticated, several important climate projection uncertainties are still actually unsolved and represent motivations for future improvements. These uncertainties concern the correct land surface representation, the complex model simulation of interactions among land surfaces, oceans and the atmosphere, and the fact that several potential climate-driving forces, such as future greenhouse gas emissions, are unknown (IPCC, 2007). For these reasons several authors (Doyon et al., 2008) have suggested that future mortality estimations only represent the starting point to quantify the magnitude of temperature-related mortality based on climate change. Moreover, in this study we only investigated the predicted mortality change due to the short-term effect of temperature for the following years. For this reason results on cold effects might be under-estimated because delayed (or long-term) temperature effects are not taken into account. However, the choice to focus our attention on the short-term effect of temperature on human health is also based on the need to improve future public health emergency responses when sudden environmental phenomenon, such as "not only extreme" high temperatures or cold air outbreaks, occur.

Furthermore, predictions of future mortality variations are generally based on a stationary relationship, without considering the potential physiological, behavioral and technological adaptation of the population that could change over time (demographic change uncertainty). The emission scenario used in this study (A1B) envisages a rapid introduction of new and more efficient technologies by 2100 . However, failing to account for possible acclimatization means that the results could be over-estimated (Gosling et al., 2009), especially those concerning future heat-related health risks: it is plausible to hypothesize an improved adaptation of the elderly population especially through the implementation of preventive health measures that will help to increase the temperature threshold critical for the health. Furthermore, Gosling et al. (2009) also suggested to evaluate the impacts of demographic changes on future temperature-related mortalities by using the SRES (Special Report on Emissions Scenarios) global population growth scenario. However, since these global projections cannot reflect any regional population changes, such as regional differences in mortality rates and migration, this approach was not applied in the present study.

Another limitation is represented by the fact that the analyses were not controlled for other meteorological parameters, biometeorological index values (i.e. apparent temperature) or air pollution levels because retrospective data were not available for all cities and future projections are not provided. However, in a previous investigation, other authors (Hajat et al., 2006) concluded that the daily apparent temperature represents a worse predictor of mortality compared to the daily mean air temperature also for an Italian city (Milan). It is known from literature that several air pollutants might contribute to temperature-related mortality (Ren et al., 2006). However, several recent studies (Anderson and Bell, 2009; Goldberg et al., 2011; McMichael et al., 2008; Williams et al., 2012) also reported that the temperature-mortality relationship is not, or is only slightly confounded by air pollutants, also suggesting that the interactions among weather, air pollution and health are strongly dependent on the city's location. Future studies should also try to account for these potential confounders. Moreover, we were not able to directly investigate a typical seasonal effect such as infectious disease epidemics since no specific database was available. However, our analysis was checked for the season and, as reported in another study (Goldberg et al., 2011), the smooth function for time should have removed most of the residual effects.

\section{Conclusions}

Our findings confirm the greater impact of both cold and especially heat conditions on non-accidental mortality of the elderly population (and especially the very elderly) rather than on hospitalizations. The said impact also showed, on the small-scale (regional level), a clear geographical pattern of the temperature-related mortality with greater impact on milder coastal plain cities rather than on inland cities.

Analyses based on high-resolution city-specific climatologic scenarios showed for the first time, a slight increase for the following years of short-term cold-related mortality of the very elderly, mainly in populations living in several inland cities, where sudden temperature fluctuations and severe cold periods are not unusual. Furthermore, our findings also support the hypothesis that the decreased cold-related mortality predicted in other cities as a consequence of climate change, will probably not offset the dramatic increases in heat-related mortality. For these reasons, general increases will be expected in the annual temperature-related mortality rates of the very elderly in most of cities considered in this study during the coming years, with worst scenarios predicted in cities located in the 
coastal plain. Indeed, it is plausible to hypothesize that populations living in coastal cities are more susceptible to temperature changes and extremes due to having adapted to prevalently mild climate conditions with low daily and annual temperature variations and where extremely high temperatures occur infrequently or irregularly.

These findings represent an important contribution that should encourage efforts to implement adaptation actions. The results could be used to assist policy-making decisions, especially for planning short- and long-term health intervention strategies and mitigation aimed at preventing and minimizing the consequences of climate change on human health.

Supplementary data to this article can be found online at http:// dx.doi.org/10.1016/j.scitotenv.2012.09.056.

\section{Acknowledgments}

This study was supported and sponsored by the Regional MeteoSalute Project, Regional Health System of Tuscany, and by the MEDIATION Project, "Methodology for Effective Decision-making on Impacts and AdaptaTION", funded by the European Commission, 7th Framework Program, Theme 6 (Environment, including Climate Change), grant agreement no. 244012.

\section{References}

Analitis A, Katsouyanni K, Biggeri A, Baccini M, Forsberg B, Bisanti L, et al. Effects of cold weather on mortality: results from 15 European cities within the PHEWE project. Am J Epidemiol 2008;168:1397-408.

Anderson BG, Bell ML. Weather-related mortality: how heat, cold, and heat waves af fect mortality in the United States. Epidemiology 2009;20:205-13.

Armstrong B. Models for the relationship between ambient temperature and daily mortality. Epidemiology 2006;17:624-31.

Chiesi M, Maselli F, Moriondo M, Fibbi L, Bindi M, Running SW. Application of BIOME-BGC to simulate Mediterranean forest processes. Ecol Model 2007;206: $179-90$.

Conlon KC, Rajkovich NB, White-Newsome JL, Larsen L, O'Neill MS. Preventing cold-related morbidity and mortality in a changing climate. Maturitas 2011;69: 197-202.

Davis RE, Knappenberger PC, Michaels PJ, Novicoff WM. Seasonality of climate-human mortality relationships in US cities and impacts of climate change. Clim Res 2004;26:61-76.

De Luca d'Alessandro E, Bonacci S, Giraldi G. Aging populations: the health and quality of life of the elderly. Clin Ter 2011;162:e13-8.

Donaldson GC, Kovats RS, Keatinge WR, McMicheal AJ. Heat- and cold related mortality and morbidity and climate change. In: Maynard RL, editor. Health effects of climate change in the UK. London: Department of Health; 2001. p. 70-80.

Doyon B, Bélanger D, Gosselin P. The potential impact of climate change on annual and seasonal mortality for three cities in Québec, Canada. Int J Health Geogr 2008;22(7):

El-Zein A, Tewtel-Salem M, Nehme G. A time-series analysis of mortality and air temperature in Greater Beirut. Sci Total Environ 2004;330:71-80.

European Topic Centre on Terrestrial Environment. CORINE land cover database (version 12/2000 extended coverage). Barcelona: European Environment Agency; 2000

Fouillet A, Rey G, Wagner V, Laaidi K, Empereur-Bissonnet P, Le Tertre A, et al. Has the impact of heat waves on mortality changed in France since the European heat wave of summer 2003? A study of the 2006 heat wave. Int J Epidemiol 2008;37: 309-17.

Gasparrini A. Distributed lag linear and non-linear models in R: the package dlnm. J Stat Softw 2011;43:1-20.

Goldberg MS, Gasparrini A, Armstrong B, Valois MF. The short-term influence of temperature on daily mortality in the temperate climate of Montreal, Canada. Environ Res 2011;111:853-60.

Gosling SN, Lowe JA, McGregor GR, Pelling M, Malamud BD. Association between elevated atmospheric temperature and human mortality: a critical review of the literature. Clim Chang 2009;92:299-341.

Guest CS, Willson K, Woodward AJ, Hennessy K, Kalkstein LS, Skinner C, et al. Climate and mortality in Australia: retrospective study, 1979-1990, and predicted impacts in five major cities in 2030. Clim Res 1999;13:1-15

Hajat S, Armstrong B, Baccini M, Biggeri A, Bisanti L, Russo A, et al. Impact of high temperatures on mortality: is there an added heat wave effect? Epidemiology 2006;17(6): 632-8. [Nov].

Hajat S, Lachowycz K, Kovats RS. Heat-related and cold-related deaths in England and Wales: who is at risk? Occup Environ Med 2007;64:93-100.

Hastie T, Tibshirani R. Generalized additive models in medical research. Stat Methods Med Res 1995;4:187-96.

Iñiguez C, Ballester F, Ferrandiz J, Pérez-Hoyos S, Sáez M, López A, et al. Relation between temperature and mortality in thirteen Spanish cities. Int J Environ Res Public Health 2010;7:3196-210.
IPCC. Special report on emission scenarios: a special report of Working Group III of the Intergovernmental Panel on Climate Change. In: Nakićenović N, Swart R, editors. UK: Cambridge University Press; 2000.

IPCC. Climate change 2007: the physical science basis. Contribution of Working Group I to the fourth assessment report of the Intergovernmental Panel on Climate Change. In: Solomon S, Qin D, Manning M, Chen Z, Marquis M, Averyt KB, et al., editors. Cambridge, United Kingdom and New York, NY, USA: Cambridge University Press; 2007.

Kalkstein IS, Davis RE. Weather and human mortality: an evaluation of demographic and inter-regional responses in the United States. Ann Assoc Am Geogr 1989;79: $44-64$.

Kalkstein LS, Greene JS. An evaluation of climate/mortality relationships in large U.S. cities and the possible impacts of a climate change. Environ Health Perspect 1997;105: $84-93$.

Keatinge WR, Donaldson GC, Cordioli E, Martinelli M, Kunst AE, Mackenbach JP, et al. Heat related mortality in warm and cold regions of Europe: observational study. BMJ 2000a;321:670-3.

Keatinge WR, Donaldson GC, Bucher K, Jendritzky G, Cordioli E, Martinelli M, et al. Winter mortality in relation to climate. Int J Circumpolar Health 2000b:59:154-9.

Knowlton K, Lynn B, Goldberg RA, Rosenzweig C, Hogrefe C, Rosenthal JK, et al. Projecting heat-related mortality impacts under a changing climate in the New York City region. Am J Public Health 2007;97:2028-34.

Kovats R, Hajat S. Heat stress and public health: a critical review. Annu Rev Public Health 2008;29:22-37.

Kovats SR, Hajat S, Wilkinson P. Contrasting patterns of mortality and hospital admissions during hot weather and heat waves in Greater London, UK. J Occup Environ Med 2004:61:893-8.

Laaidi M, Laaidi K, Besancenot JP. Temperature-related mortality in France, a comparison between regions with different climates from the perspective of global warming. Int J Biometeorol 2006;51:145-53.

Langford IH, Bentham G. The potential effects of climate change on winter mortality in England and Wales. Int J Biometeorol 1995;38:141-7.

Lin S, Luo M, Walker RJ, Liu X, Hwang SA, Chinery R. Extreme high temperatures and hospital admissions for respiratory and cardiovascular diseases. Epidemiology 2009;20:738-46.

Linares C, Díaz J. Impact of high temperatures on hospital admissions: comparative analysis with previous studies about mortality (Madrid). Eur J Public Health 2008;18:317-22.

Martin SL, Cakmak S, Hebbern CA, Avramescu ML, Tremblay N. Climate change and future temperature-related mortality in 15 Canadian cities. Int J Biometeorol 2011. http://dx.doi.org/10.1007/s00484-011-0449-y.

Mastrangelo G, Hajat S, Fadda E, Buja A, Fedeli U, Spolaore P. Contrasting patterns of hospital admissions and mortality during heat waves: are deaths from circulatory disease a real excess or an artifact? Med Hypotheses 2006;66:1025-8.

McGeehin MA, Mirabelli M. The potential impacts of climate variability and change on temperature-related morbidity and mortality in the United States. Environ Health Perspect 2001;109(Suppl. 2):185-9.

McMichael AJ, Haines A, Sloof R, Kovats S. Climate change and human health. Geneva: World Health Organization; 1996.

McMichael AJ, Woodruff RE, Hales S. Climate change and human health: present and future risks. Lancet 2006;367:859-69.

McMichael AJ, Wilkinson P, Kovats RS, Pattenden S, Hajat S, Armstrong B, et al. International study of temperature, heat and urban mortality: the 'ISOTHURM' project. Int J Epidemiol 2008;37:1121-31.

Medina-Ramón M, Schwartz J. Temperature, temperature extremes, and mortality: a study of acclimatization and effect modification in 50 US cities. Occup Environ Med 2007;64:827-33.

Morabito M, Crisci A, Orlandini S, Maracchi G, Gensini GF, Modesti PA. A synoptic approach to weather conditions discloses a relationship with ambulatory blood pressure in hypertensives. Am J Hypertens 2008;21:748-52.

Morabito M, Crisci A, Vallorani R, Modesti PA, Gensini GF, Orlandini S. Innovative approaches helpful to enhance knowledge on weather-related stroke events over a wide geographical area and a large population. Stroke 2011;42:593-600.

Morabito M, Profili F, Crisci A, Francesconi P, Gensini GF, Orlandini S. Heat-related mortality in the Florentine area (Italy) before and after the exceptional 2003 heat wave in Europe: an improved public health response? Int J Biometeorol 2012;56:801-10.

Muggeo VM. Estimating regression models with unknown break-points. Stat Med 2003;22:3055-71.

Muggeo VM. Modeling temperature effects on mortality: multiple segmented relationships with common break points. Biostatistics 2008;9:613-20.

Muggeo VM. Analyzing temperature effects on mortality within the R environment: the constrained segmented distributed lag parameterization. J Stat Softw 2010;32: $1-17$

Muggeo VM, Hajat S. Modelling the non-linear multiple-lag effects of ambient temperature on mortality in Santiago and Palermo: a constrained segmented distributed lag approach. Occup Environ Med 2009;66:584-91.

R Development Core Team. R: a language and environment for statistical computing. Vienna, Austria: R Foundation for Statistical Computing3-900051-07-0; 2011 [http://www.R-project.org/].

Ren C, Williams GM, Tong S. Does particulate matter modify the association between temperature and cardiorespiratory diseases? Environ Health Perspect 2006;114: 1690-6.

Semenov MA, Barrow EM. Use of a stochastic weather generator in the development of climate change scenarios. Clim Chang 1997;35:397-414.

The Eurowinter Group. Cold exposure and winter mortality from ischaemic heart disease, cerebrovascular disease, respiratory disease, and all causes in warm and cold regions of Europe. The Eurowinter Group. Lancet 1997;349:1341-6. 
Thornton PE, Running SW, White MA. Generating surfaces of daily meteorological variables over large regions of complex terrain. J Hydrol 1997;190:214-51.

United Nations, Department of Economic and Social Affairs, Population Division. World population prospects: the 2010 revision. CD-ROM Edition; 2011.

Williams S, Nitschke M, Weinstein P, Pisaniello DL, Parton KA, Bi P. The impact of summer temperatures and heatwaves on mortality and morbidity in Perth, Australia 1994-2008. Environ Int 2012;40:33-8.
Wood SN. Generalized additive models: an introduction. Chapman \& Hall/CRC; 2006.

Ye X, Wolff R, Yu W, Vaneckova P, Pan X, Tong S. Ambient temperature and morbidity: a review of epidemiological evidence. Environ Health Perspect 2012;120:19-28.

Yu W, Mengersen K, Wang X, Ye X, Guo Y, Pan X, et al. Daily average temperature and mortality among the elderly: a meta-analysis and systematic review of epidemiological evidence. Int J Biometeorol 2011. http://dx.doi.org/10.1007/s00484-011-0497-3. 